\title{
GEOELECTRICAL RESISTIVITY SURVEY FOR GROUNDWATER POTENTIAL - A CASE STUDY OF NANDI RIVER BASIN, TAMIL NADU, INDIA
}

\author{
PRABHU, K. ${ }^{1,2^{*}}-$ SIVAKUMAR, R. ${ }^{1}$ \\ ${ }^{1}$ Department of Civil Engineering, SRM Institute of Science and Technology \\ Kattankulathur, India \\ ${ }^{2}$ Department of Civil Engineering, GRT Institute of Engineering \& Technology, Tiruttani, India \\ *Corresponding author \\ e-mail: k.prabhumtech@gmail.com; phone: +91-97-9061-4711
}

(Received $8^{\text {th }}$ Oct 2017; accepted $27^{\text {th }}$ Feb 2018)

\begin{abstract}
Ground water plays a vital role in the development of human activities. The supply of groundwater is limited and understanding the groundwater system is important to ensure sustainable use. In the present study Geoelectrical resistivity survey was carried out to assess groundwater potential zones in Nandi river basin, Tamil Nadu, India. The Vertical Electrical Soundings (VES) of Schlumberger configuration survey was conducted at 27 locations up to a depth of $150 \mathrm{~m}$. The results of VES data were interpreted using IPI2WIN software. The resultant VES curves show different layers of sub-surface true resistivity and subsequent thickness are generated for understanding the lithology and hydrogeological conditions of the study area. The natural resources of groundwater potential zones are identified from the true resistivity and its thickness of sub surface layer.
\end{abstract}

Keywords: groundwater, vertical electrical sounding, resistivity, hydrogeological, natural resources

\section{Introduction}

Groundwater is a most valuable natural resource for irrigation, domestic and other purposes of water necessities in many parts of India. About $70 \%$ of the total amount of freshwater on Earth is contained in rivers, lakes, and glaciers. About $30 \%$ is contained in aquifers as groundwater (Salas et al., 2014). Shereif H. Mahmoud (2014) states that in water resource planning, groundwater is attracting increased attention due to the shortage of high-quality subsurface water for drinking and the increasing need of water for domestic, agricultural and industrial use. It has become crucial not only to target potential zones of groundwater but also to monitor and conserve this important resource. The scarcity of freshwater is the main problem faced by many countries exacerbated by the increasing population which creates the increasing need of the freshwater.

Groundwater is more advantageous as a source of portable water because it is free from chemical and biological contaminants, if it is properly saved it needs less or no purification before it can be used for industrial and domestic purposes. Most of the people depend upon groundwater as a source of water for all activities like drinking, agriculture and domestic use (Ahamed et al., 2016). Generally, it occurs in subsurface geological formations under hydrostatic pressure in the pores and cracks of rocks. The study area also geologically consists of crystalline rocks of various ages. In India, over two-thirds of the surface area totaling about 2.40 million sq. $\mathrm{km}$. is occupied by hard rock regions and nearly $50 \%$ of the replenishable resources of groundwater occur in these rocks (Singhal, 2008). The movement and occurrence of groundwater are 
extensively controlled by weathering and fractures of hard rock beneath the surface of the study area. Hydrogeologically the weathered rock has a porosity and contains a considerable quantity of water, because of its moderately high clay content, as it has a low permeability (Krishnamurthy et al., 2008). The preservation, planning, and governance of groundwater resources is the daunting challenges in the hard rock areas. Also, the groundwater potential have been affected by the rapid climate change (Shakib and Shojarastegari, 2017).

Since the quality and quantity of groundwater are associated with the subsurface conditions of the Earth, the geophysical survey plays a vital role in understanding the occurrence and distribution of groundwater in different hydrogeological circumstances. A wide range of geophysical survey methods are used in mining, in the industrial and environmental sectors. Geophysical survey methods are cost-effective and environmentally safer and there is no disturbance of subsurface materials (Reynolds, 2011). Vast areas of the surface field can be surveyed quickly at relatively less expensive, providing information to aid the location of boreholes. The principal methods used in geophysical exploration include seismic, gravity, magnetic, electrical resistivity, self- potential, induced polarization, and electromagnetic method. The use of geophysical surveys have increased tremendously over the last decades. Hence, the suitable geophysical resistivity survey methods are deployed based on the physical properties of a target being investigated.

\section{Study area}

The study area "Nandi river basin" falls within the part of two districts of Tamil Nadu namely Tiruvallur and Vellore Districts and a small adjoining part of Chittoor District of Andhra Pradesh. The study area lies between the latitudes $13^{\circ} 03^{\prime} 28^{\prime \prime} \mathrm{N}$ to $13^{\circ} 15^{\prime} 59^{\prime \prime} \mathrm{N}$ and longitudes $79^{\circ} 17^{\prime} 30^{\prime \prime} \mathrm{E}$ to $79^{\circ} 43^{\prime} 25^{\prime \prime} \mathrm{E}$ covering an area of $710 \mathrm{~km}^{2}$ (Fig. 1).

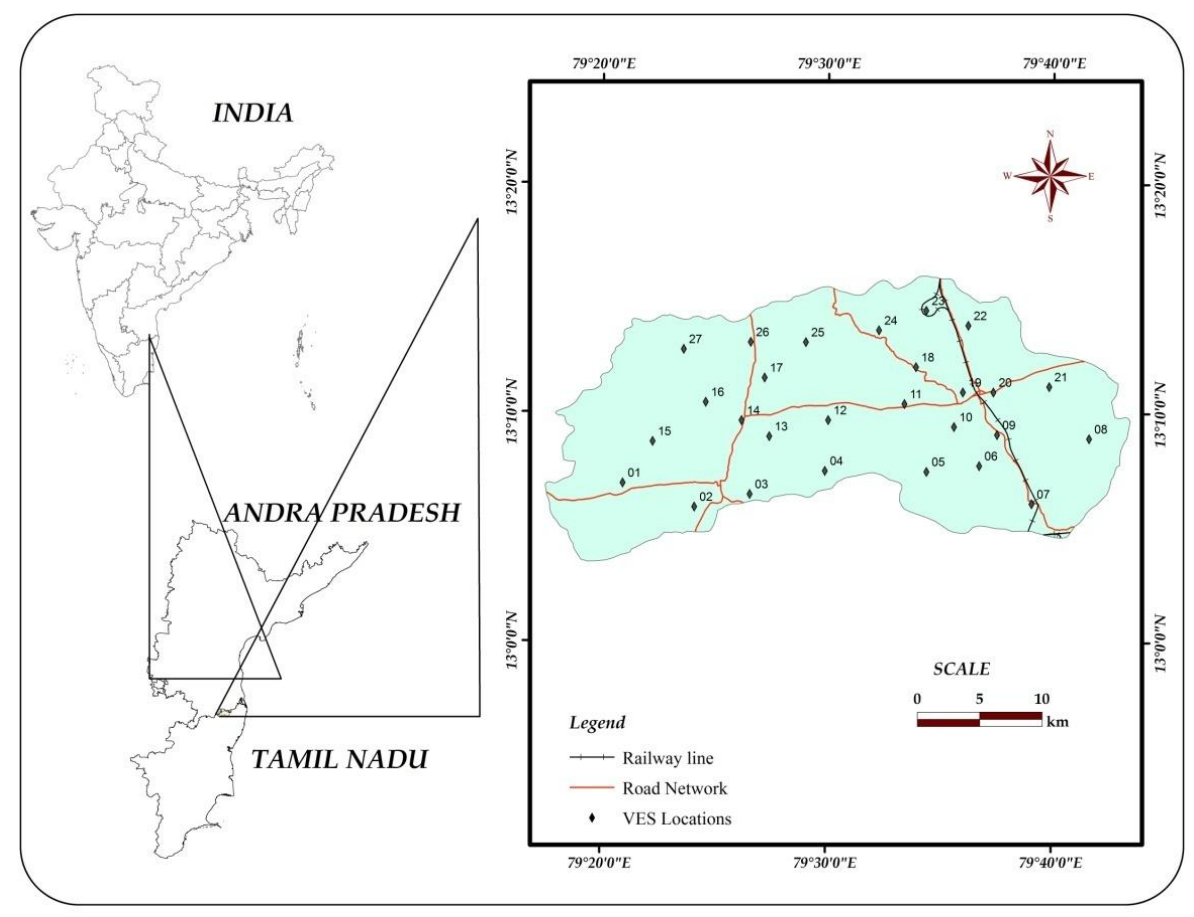


Figure 1. Base map of the study area

The Nandi river originates from Puttur hills at an altitude of 582 m near Singasamudram in Andhra Pradesh, and it enters Tamil Nadu and feeds the Sholingur tank. The surplus of this tank feeds the Viranatturu tank and from this tank, the river takes a regular course. The chief irrigation sources in the area are the tanks, wells, and tube/bore wells.

The study area receives $795 \mathrm{~mm}$ rainfall as an annual average, of which $535 \mathrm{~mm}$ is contributed by the northeast monsoon, and the rest by the southwest monsoon. Although the study area has a lack of rainfall, agriculture is not extensively practiced in the region. Crops like paddy, sugarcane and mango tree are planted in some areas, which are the main sources of income for the majority of residents.

\section{Geology}

The geology of the area is important for determining the influence of its physiographic characteristics. The main purpose of investigating the geology of a river basin is a hydrological project to determine the permeability of the substratum (Musy and Higy, 2011). The porosity and permeability of the rock formation considerably influence the flow of groundwater. Hence, the knowledge of porosity and permeability of rock formation gives an insight into the groundwater supply and its flow paths. The study area above a permeable substratum transmits considerable amount of water to the aquifers in the rainy events so that during dry periods, the water can be extracted as groundwater.

The study area is essentially composed of several crystalline rocks as well as sedimentary rocks, shown in Figure 2.

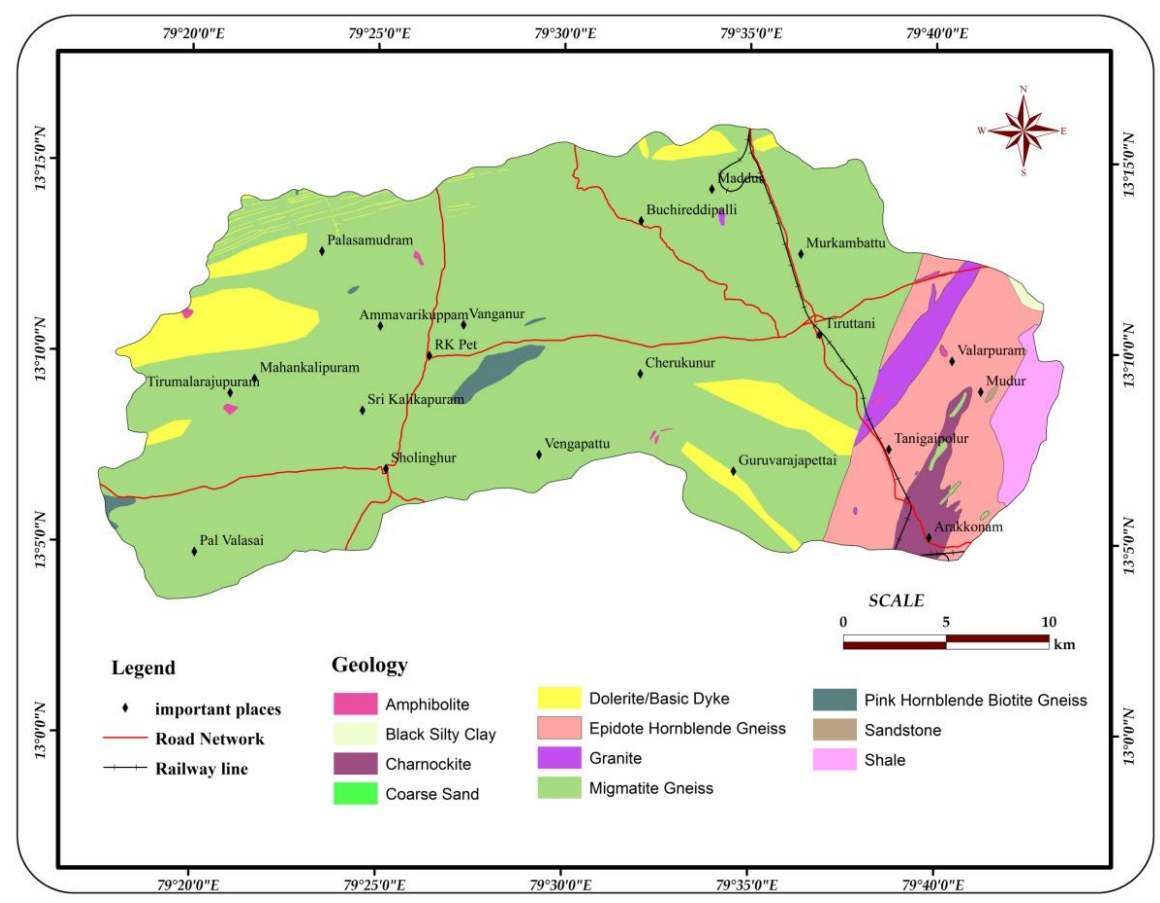

Figure 2. Geology map of the study area

Migmatite gneiss is the major rock, covering about $547.39 \mathrm{~km}^{2}(77 \%)$ of the total study area, Followed by Epidote hornblende gneiss with a spatial extent of $68.32 \mathrm{~km}^{2}$. The 
younger sedimentary rocks include shale $\left(14.78 \mathrm{~km}^{2}\right)$, sandstone $\left(0.20 \mathrm{~km}^{2}\right)$, black silty clay $\left(0.96 \mathrm{~km}^{2}\right)$ and coarse sand $\left(0.04 \mathrm{~km}^{2}\right)$ covered $2.25 \%$ of the study area. Dolerite dykes are found as isolated linear bodies, reserving about $47.50 \mathrm{~km}^{2}$. The remaining rock types include amphibolite, charnockite, granite, and pink hornblende-biotite gneiss, each covering small portions of the study area. The Archaen crystalline rock is underlain in the subsurface geology of the study area; hence the groundwater may infiltrate in the weathered zone and fractured rocks. So the fractures play a significant and crucial role in fluid flow, particularly for the movement and accumulation of groundwater in hard rock areas. If minor fracture interconnections are present in the rock, those give numerous supply of groundwater.

\section{Materials and methods}

In VES survey, the direct current is injected into the surface of the Earth through two current electrodes and the resultant potential variations are measured at the surface with the help of a voltmeter connecting two potential electrodes. The conductive property of rock is essential to have knowledge about the mode of conduction through various materials. At most, rocks are poor conductors, the resistivity of theirs rocks would be pretty large. In some cases, the fractures and pore spaces present in the rocks are filled with water which has dissolved minerals derived from weathering of rocks. The dissolved minerals tend to disintegrate into positively charged cations and negatively charged anions, moving through the water in opposite directions. This movement of ions opposite to each other initiates ionic conduction process. Thus the rocks act as electrolytic conductors where the current is carried by Total Dissolved Solids (TDS) present in the water. Hence the resistivity of a rock depends on the mobility and concentration of TDS in water, the volume and arrangement of the pore spaces.

A detailed knowledge of geology is the most important aspects for classifying the Earth's layers because the rocks exhibit a wide range of electrical resistivity. For instance, igneous rocks tend to have the highest resistivity, sedimentary rocks are the most conductive, largely due to their high pore fluid content and metamorphic rocks contain transitional but the overlapping resistivity (Reynolds, 2011). A successful result of the survey depends on meticulous planning in site selection and data acquisition. The electrical resistivity prospecting of the basic electric parameters of electric current, potential difference, resistance and apparent resistivity which is together used to derive the true resistivity of Earth's layers during data processing. Electric current is measured by the ammeter and is expressed in amps whereas the potential difference by a voltmeter, expressed in terms of volts. The Potential difference is just an electrical pressure difference required to make an electric current flow. Commonly an increase in potential difference boosts the current flow through the rocks. According to Ohm's law, the resistance of a rock is the ratio of potential difference $(\Delta v)$, and the current (I), i.e. $R$ $=\Delta \mathrm{v} / \mathrm{I}$, measured in ohms. The primary aim of the VES survey is to obtain the true resistivity of a rock layer for the subsurface; but the Earth is not composed of homogenous materials, and it is not possible to measure the true resistivity of the rock directly. Instead, apparent resistivity $\left(\rho_{\mathrm{a}}\right)$ is measured by multiplying the resistance $(\mathrm{R})$ with the geometric factor $(K)$ of the electrode array chosen for the investigation; the $\rho_{a}$ varies with the electrode array type. 
Then the true resistivity $(\rho)$ of the rock layer is obtained through the manual curve matching technique or computer programs during data processing. There are three primary types of electrode configuration Wenner, Schlumberger, and dipole-dipole array are employed in geophysical method. For the present study the Schlumberger array has been used. When comparing the electrode configuration, Schlumberger sounding can be conducted faster, since the movement of the electrodes is mainly confined to the current electrodes only, while during the entire sounding, the potential electrodes may have to be shifted four times altogether (Ramanuja Chary, 2012).

\section{Field procedure}

In total 27 VES survey locations were selected over the study area and the electrical investigation data were collected at the specific locations using DDR-3 Resistivity Meter. The Geoelectrical resistivity survey was carried out during the month of July 2016 and at every survey location 37 observations were carried out. The investigation for each VES location was started at $2 \mathrm{~m}$ depth and was completed at $150 \mathrm{~m}$ depth which is the maximum depth of investigation. The Schlumberger configuration of VES survey carried out the maximum electrode spacing of $300 \mathrm{~m}$ as shown in Figure 3. The current electrode $(\mathrm{AB} / 2)$ spacing varied from 1 to $150 \mathrm{~m}$ and the potential electrode $\left(\mathrm{P}_{1} \mathrm{P}_{2} / 2\right)$ spacing varied from 1 to $20 \mathrm{~m}$.

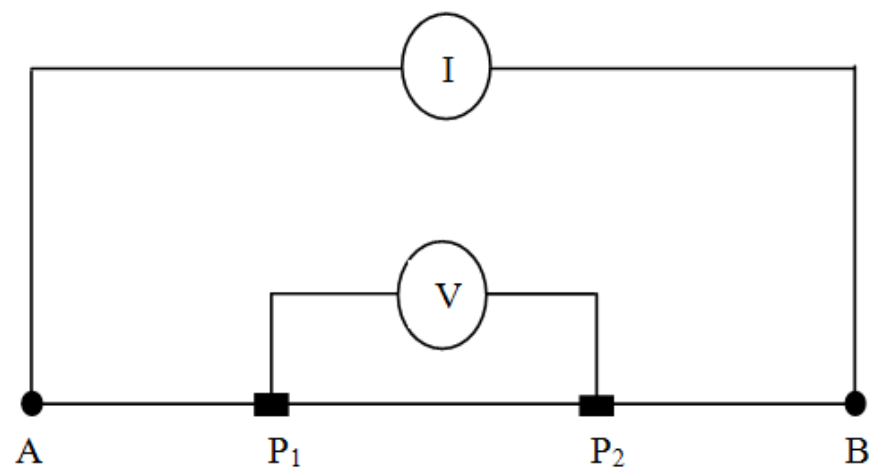

Figure 3. VES survey electrode arrangement

The measured apparent resistivity values were plotted on a logarithmic graph against the half-electrode spacing $(\mathrm{AB} / 2)$ values using the software IPI2WIN. The resulting VES curves, known as sounding curves were adjusted until the minimum RMS error was achieved. Four layered curve types were generated with the aid of the software. Curve types were classified based on the relative resistivity values of layers and were used for qualitative and quantitative interpretation.

\section{Results and discussion}

The field data were interpreted and processed quantitatively and qualitatively by using curve matching techniques. The quantitative interpretation involves the determination of the number of geoelectrical layers as well as the true depth, thickness, and resistivity of each layer (Barseem, 2015). The true resistivity and thickness of layers for quantitative analysis of VES represented in Table 1. The qualitative interpretation 
provides an insight into curve shape, curve type, and the number of layers that are represented in Table 2.

Table 1. Resistivity and thickness of layers for quantitative analysis of VES

\begin{tabular}{|c|c|c|c|c|c|c|c|c|}
\hline \multirow{2}{*}{$\begin{array}{c}\text { VES } \\
\text { no. }\end{array}$} & \multirow{2}{*}{ Village name } & \multicolumn{4}{|c|}{ Resistivity (ohm-m) } & \multicolumn{3}{|c|}{ Layer thickness (m) } \\
\hline & & $\rho_{1}$ & $\rho_{2}$ & $\rho_{3}$ & $\rho_{4}$ & $\mathbf{h}_{1}$ & $\mathbf{h}_{2}$ & $\mathbf{h}_{3}$ \\
\hline 1 & Gopalapuram & 75.5 & 166 & 683 & 904 & 2.17 & 15.8 & 117 \\
\hline 2 & Misarakandapuram & 12.4 & 248 & 493 & 558 & 1.6 & 53.5 & 132 \\
\hline 3 & Sholinghur & 12 & 221 & 43.1 & 62139 & 1.13 & 7.61 & 10.2 \\
\hline 4 & Vangapattu & 10.6 & 222 & 37.6 & 935 & 1.42 & 1.65 & 9.19 \\
\hline 5 & Guruvarajapet & 63.8 & 772 & 134 & 901 & 1.43 & 1.22 & 4.02 \\
\hline 6 & Gadavarikandigai & 50.2 & 88.3 & 869 & 214 & 1.18 & 8.82 & 15.2 \\
\hline 7 & Arakkonam & 23.5 & 311 & 160 & 1710 & 2.08 & 3.89 & 32.5 \\
\hline 8 & Mudur & 13.9 & 479 & 13 & 599 & 3.39 & 3.08 & 6.68 \\
\hline 9 & Saraswathi Nagar & 103 & 204 & 754 & 924 & 3.33 & 9.04 & 37.7 \\
\hline 10 & Kannika Puram & 216 & 956 & 123 & 3180 & 1.5 & 4.01 & 4.84 \\
\hline 11 & Koramangalam & 11.2 & 535 & 29.1 & 36638 & 1.47 & 2.79 & 7.16 \\
\hline 12 & Beerakuppam & 72.5 & 311 & 3941 & 8025 & 2.37 & 10.7 & 7.25 \\
\hline 13 & Vellathur & 25.1 & 272 & 112 & 845 & 1.31 & 8.69 & 5.85 \\
\hline 14 & Ramakrishnaraja Pet & 2.76 & 531 & 17.1 & 17724 & 0.697 & 3.6 & 11.4 \\
\hline 15 & Mahankalikapuram & 71.4 & 251 & 77.2 & 325 & 1.14 & 0.69 & 14.2 \\
\hline 16 & Ammaiyarkuppam & 94.2 & 41.7 & 978 & 645 & 4.99 & 8.16 & 5.44 \\
\hline 17 & Vanganur & 36.6 & 268 & 30.9 & 51283 & 1.07 & 1.72 & 6.49 \\
\hline 18 & Thekkaloor & 220 & 3162 & 113 & 2245 & 1.2 & 1.26 & 11.4 \\
\hline 19 & Tiruttani (Sai Baba Nagar) & 13.9 & 344 & 61 & 924 & 1.07 & 3.03 & 15.5 \\
\hline 20 & Tiruttani (Erular Colony) & 40.3 & 85.5 & 16.4 & 210 & 2.12 & 2.23 & 11.9 \\
\hline 21 & Perungalathur & 11.7 & 41.2 & 12 & 12649 & 1.96 & 1.33 & 3.69 \\
\hline 22 & Ponpadi & 19.7 & 1.66 & 5.92 & 830 & 1.05 & 1.04 & 3.83 \\
\hline 23 & Mathur & 11.2 & 23 & 73 & 307 & 1.24 & 4.79 & 12.3 \\
\hline 24 & B.R. Palli & 113 & 577 & 162 & 1676 & 1.12 & 0.448 & 8.78 \\
\hline 25 & Nochili & 48.3 & 78.9 & 200 & 3875 & 1.61 & 10 & 29.8 \\
\hline 26 & Korakuppam & 17.9 & 10.8 & 34.8 & 11836 & 1.7 & 1.82 & 5.94 \\
\hline 27 & Palasamudram & 69 & 43.1 & 94.5 & 675 & 1.12 & 3.44 & 15.3 \\
\hline
\end{tabular}

Table 2. Curve types for qualitative analysis of VES

\begin{tabular}{c|c|c|c}
\hline VES no's & $\begin{array}{c}\text { Curve } \\
\text { characteristics }\end{array}$ & Curve type & Layers \\
\hline $3,4,5,7,8,10,11,13,14,15,17,18,19,20,21,24$ & $\rho_{1<} \rho_{2}>\rho_{3}<\rho_{4}$ & $\mathrm{KH}$ & 4 \\
\hline $1,2,9,12,23,25$ & $\rho_{1<} \rho_{2}<\rho_{3}<\rho_{4}$ & $\mathrm{AA}$ & 4 \\
\hline 16 & $\rho_{1>} \rho_{2}<\rho_{3}>\rho_{4}$ & $\mathrm{HK}$ & 4 \\
\hline $22,26,27$ & $\rho_{1}>\rho_{2}<\rho_{3}<\rho_{4}$ & $\mathrm{HA}$ & 4 \\
\hline 6 & $\rho_{1>}>\rho_{2}>\rho_{3}<\rho_{4}$ & $\mathrm{QH}$ & 4 \\
\hline
\end{tabular}




\section{KH-type curve}

The KH curves are morphologically characterized by the resistive sequence of $\rho_{1}<\rho_{2}>\rho_{3}<\rho_{4}$. In general, the VES profiles belonging to this curve type show highly conductive top soil layer, and relatively high resistance in bottom layers, indicating the possibility of water saturation in the third layer, most of which possess highly contrasting low resistivity values between the second and fourth layers. Figure 4 shows the interpretation of VES curves (KH-Type) using the IPI2WIN software.

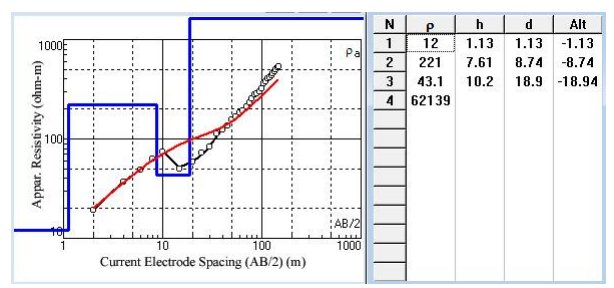

VES 3

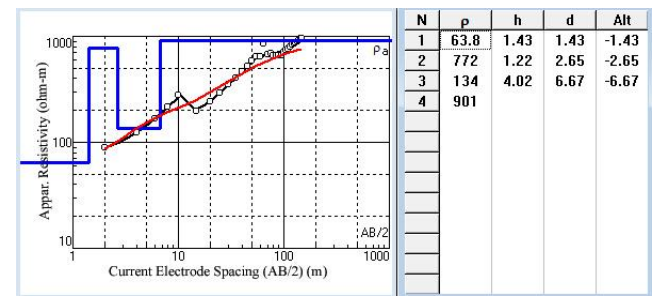

VES 5

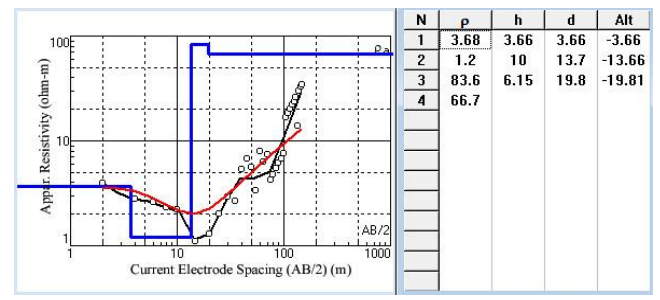

VES 8

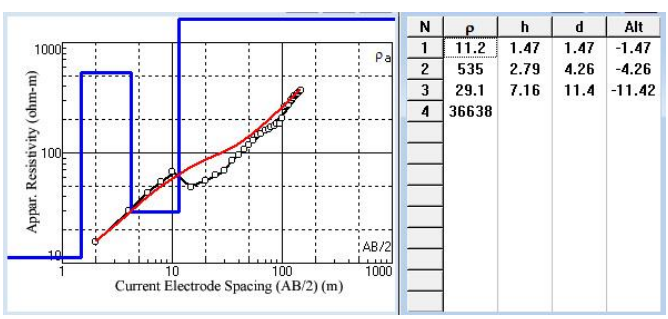

VES 11

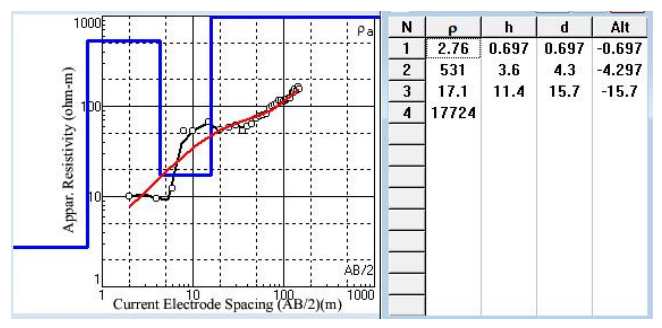

VES 14

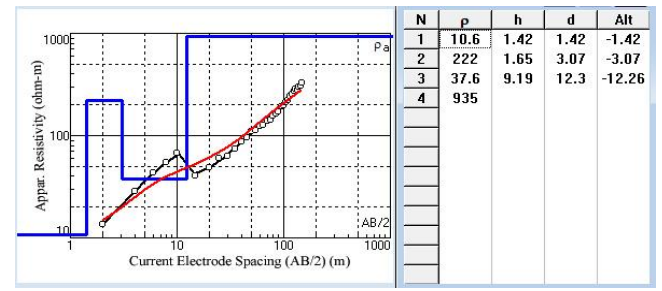

VES 4

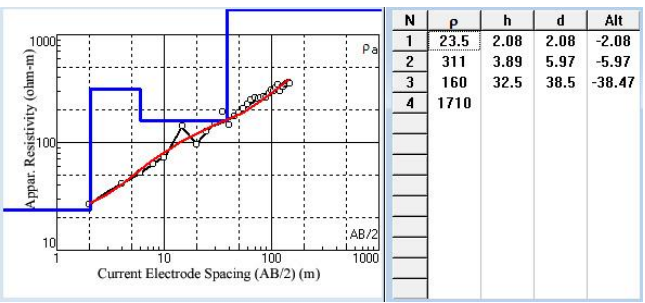

VES 7

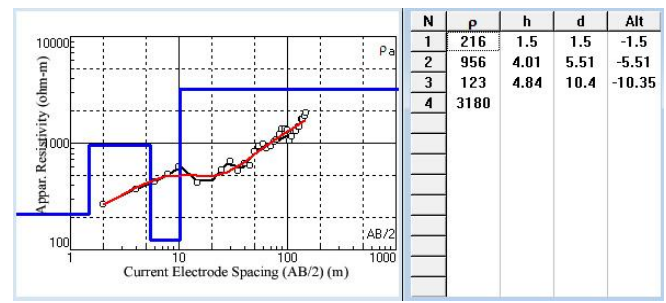

VES 10

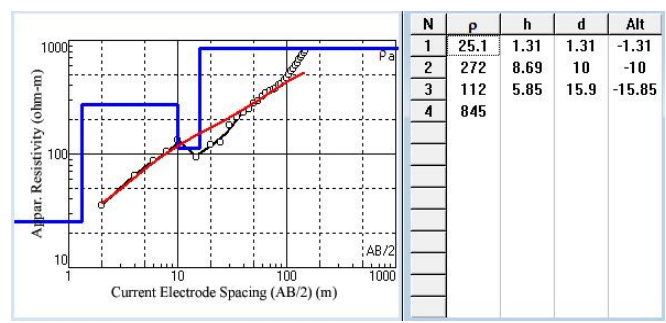

VES 13

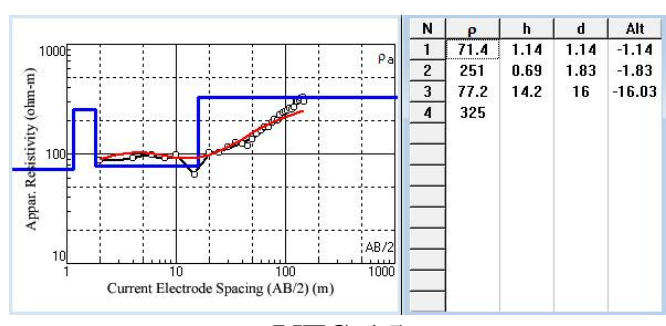

VES 15 


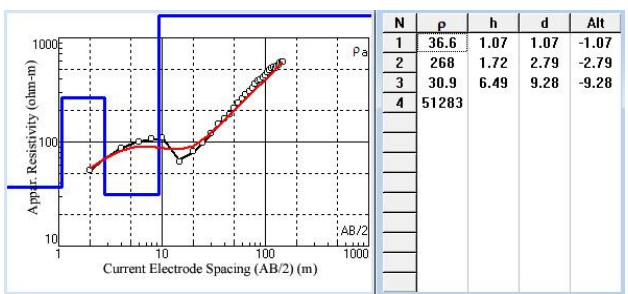

VES 17

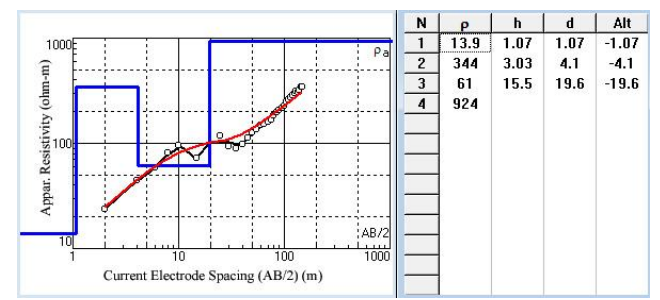

VES 19

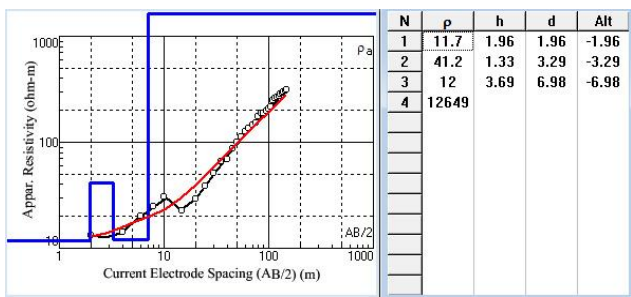

VES 21

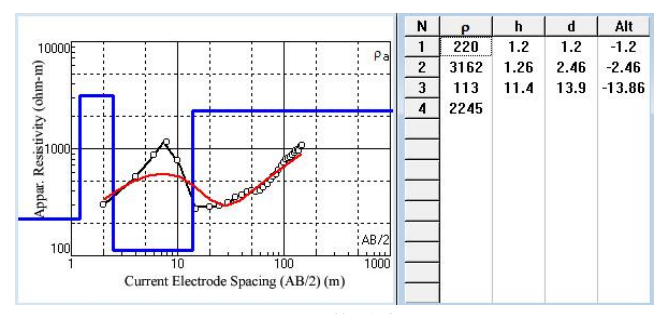

VES 18

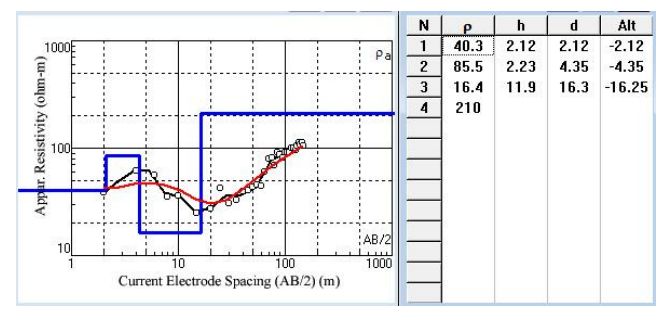

VES 20

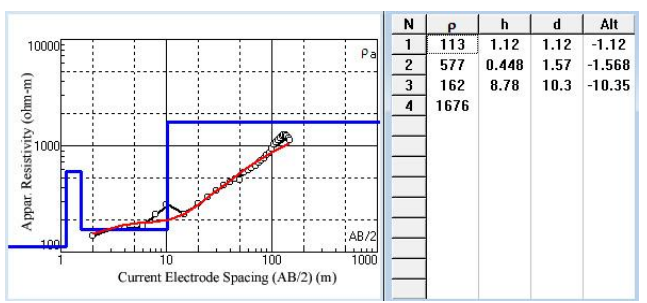

VES 24

Figure 4. Interpretation of VES curves - KH-type

VES 3, 4, 7, 8, 11, 13, 14, 17, 19 and 21 show the topsoil layers with resistivity ranges from $2.76 \mathrm{ohm}-\mathrm{m}$ to $36.6 \mathrm{ohm}-\mathrm{m}$, indicating the presence of clay constituents between $20 \%$ to $40 \%$ in soil (Reynolds, 2011) and varying in thicknesses from $0.697 \mathrm{~m}$ to $3.39 \mathrm{~m}$; while VES 5, 10, 15, 18, 20 and 24 exhibit topsoil layers with resistivity values ranging from $40.3 \mathrm{ohm}-\mathrm{m}$ to $220 \mathrm{ohm}-\mathrm{m}$, revealing the soil composition with lack of clay content and the thicknesses vary from $1.12 \mathrm{~m}$ to $2.12 \mathrm{~m}$.

Commonly, all VES curves of the KH represent the third layer as the fractured layer filled with water. Hence, based on the third layer thickness, its original depth, and its resistivity contrast with its overlying and underlying layers, the degree of groundwater potential has been inferred from a VES curve. Accordingly, VES 3, 7, 10, 11, 13, 14, 17, 19, 20 and 21 can be indicative of good groundwater yield, while VES 4, 5, 8, 15, 18 and 24 display the origin of third layers at relatively shallow depth, implying the presence of clay formation or the temporary groundwater yield.

\section{AA-type curve}

The resistivity sequence of $\rho_{1}<\rho_{2}<\rho_{3}<\rho_{4}$ makes the shape of AA type curve. In most cases, the first layer starts with relatively low resistivity values and the fourth layer ends with relatively high resistivity ranges, showing the steady increase in the resistivity values as a function of depth. This is the obvious fact of the AA type curve. Figure 5 shows the interpretation of VES curves - AA-Type.

In VES 1, 2, 9, 12, 23 and 25 represent the topsoil with thickness ranges from $1.24 \mathrm{~m}$ to $3.33 \mathrm{~m}$ and resistivity ranges from $11.2 \mathrm{ohm}-\mathrm{m}$ to $103 \mathrm{ohm}-\mathrm{m}$. Hence, the low 
resistivity of topsoil depends on the proportion of clay mineral constituents in soil, the grain size, and moisture content, whereas high resistivity soil exhibits lack of moisture and clay content, and coarse-grained mineral constituents present in the soil.

VES 25 denotes the second layer as a weathered layer with the resistivity of $78.9 \mathrm{ohm}-\mathrm{m}$, followed by the third layer of $200 \mathrm{ohm}-\mathrm{m}$, pointing to the high probability of reasonable groundwater occurrence in the third layer. The weathered zone starts at $1.60 \mathrm{~m}$ down the surface and extends up to $10 \mathrm{~m}$. The third layer is a fracture zone of $29.8 \mathrm{~m}$ thickness. A rapid increase of resistivity values in the fourth layer authenticates the existence of water table confined to the third layer. Similarly, VES 12 depicts weathered zone of $10.7 \mathrm{~m}$ thickness with the resistivity of $311 \mathrm{ohm}-\mathrm{m}$, starting at $2.37 \mathrm{~m}$ below the surface and this layer is followed by relatively high resistivity layers having $3941 \mathrm{ohm}-\mathrm{m}$, indicating the possible occurrence of clay patches in the weathered zone. Also, the weathered zone may contain some amount of rainwater percolated through the soil. The resistivity of the fourth layer expresses the fresh rock formation where the occurrence of groundwater is the mostly doubtful. Below the topsoil layer, the resistivity ranges of the VES 1,2, 9 and 23 expose the absence of any fractured rock layers up to the depth of maximum investigation, leading to poor groundwater potential.

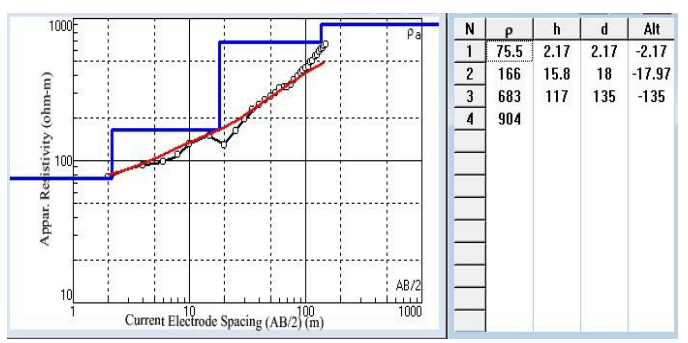

VES 1

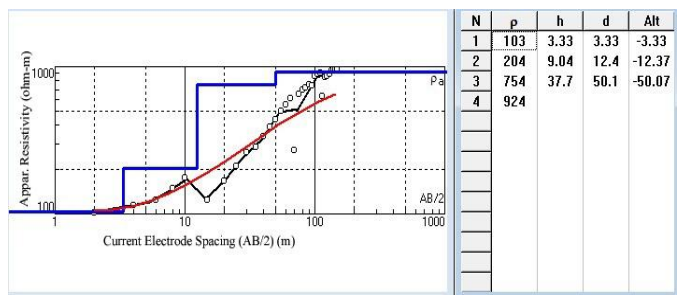

VES 9

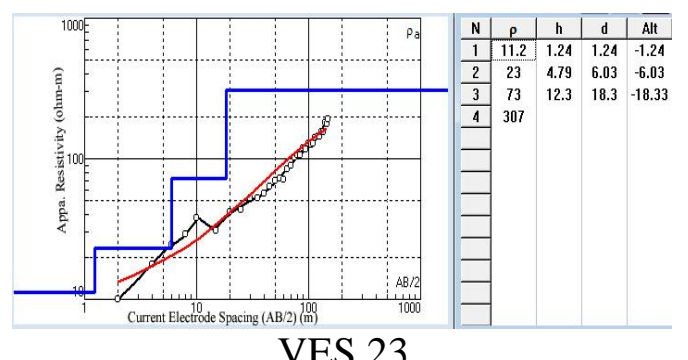

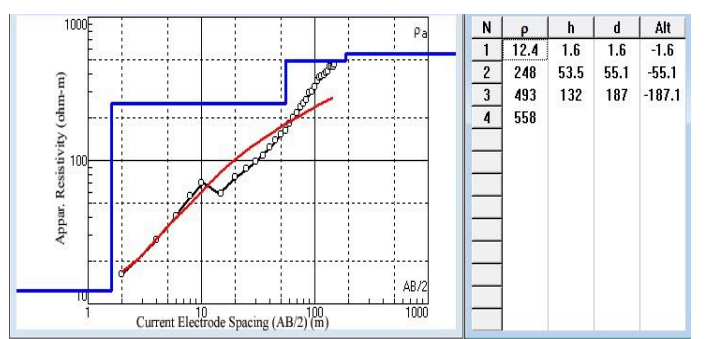

VES 2

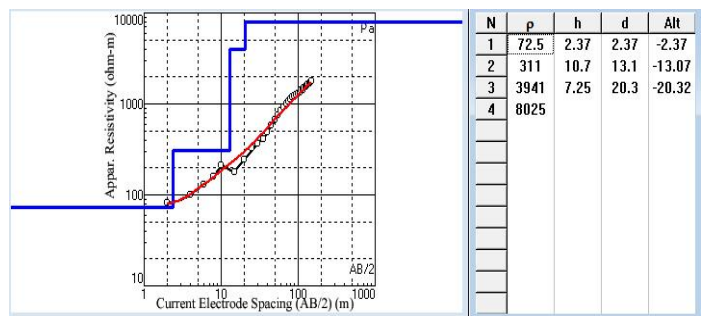

VES 12

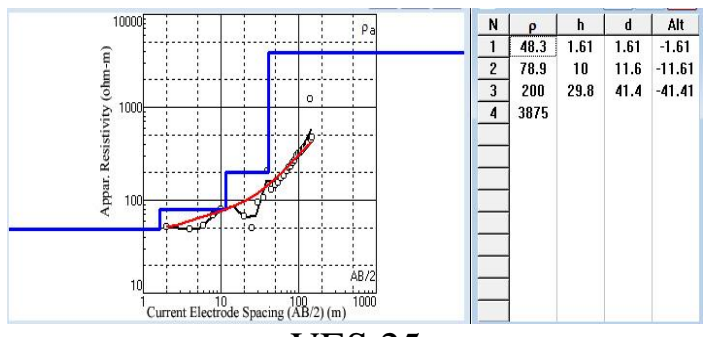

VES 25

Figure 5. Interpretation of VES curves - AA-type

\section{HK type curve}

The HK type curve is defined by the resistivity sequence of $\left.\rho_{1}\right\rangle \rho_{2}\left\langle\rho_{3}\right\rangle \rho_{4}$. The topsoil resistivity $(94.2 \mathrm{ohm}-\mathrm{m})$ of VES 16 discloses soil composition with deficient clay constituents and reveal a second layer with relatively lower resistivity values than 
the topsoil layer, ranging $41.7 \mathrm{ohm}-\mathrm{m}$. It reveals the probable existence of a clay layer or highly altered weathered zones which can act as better conduits for groundwater movement down to deep aquifers if present. The third layer shows a sudden increase in resistivity value with the indication of the absence or lack of fractured rock layers. The fourth layer is followed by the third layer with slight reduction in the resistivity value; the slightly reduced resistivity can be due to the emergence of interconnected fractures capable of yielding moderate groundwater. The interpretation of VES curves HK-Type is shown in Figure 6.

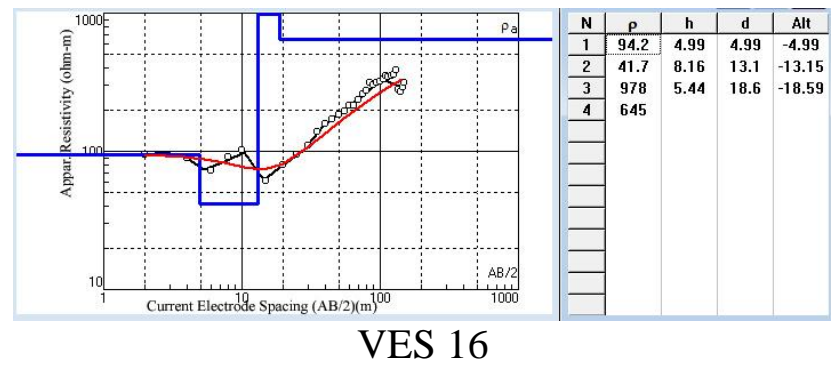

Figure 6. Interpretation of VES curves - HK-type

\section{HA type curve}

HA type curve is defined by the resistivity sequence of $\left.\rho_{1}\right\rangle \rho_{2}\left\langle\rho_{3}\right\rangle \rho_{4}$. In this curve type, the resistivity of the first layer always exceeds the resistance of the second layer, followed by a progressive increase in the resistivity of successive layers in terms of depth. In most cases, just beneath the third layer, an immediate increase is observed in the resistivity of the fourth layer which can be the sign of a massive hard rock formation. The interpretation of VES curves HK-Type is shown in Figure 7.

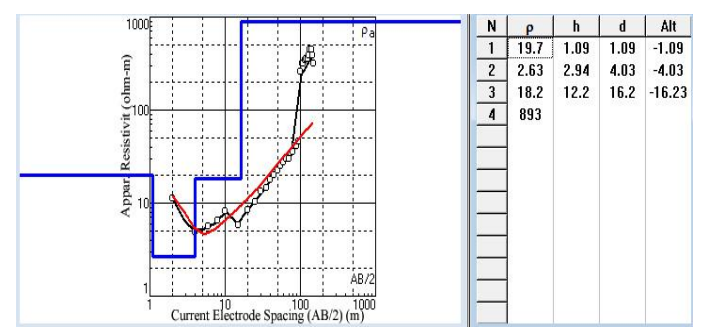

VES 22

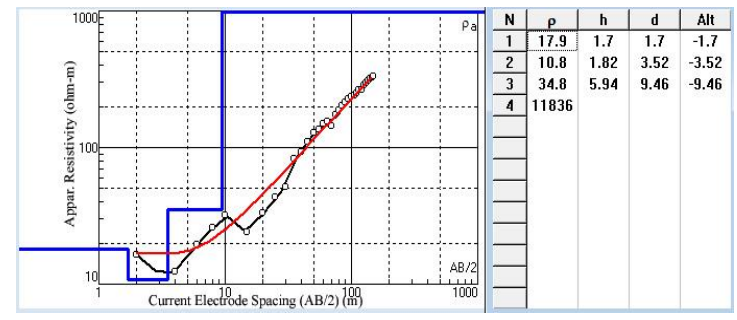

VES 26

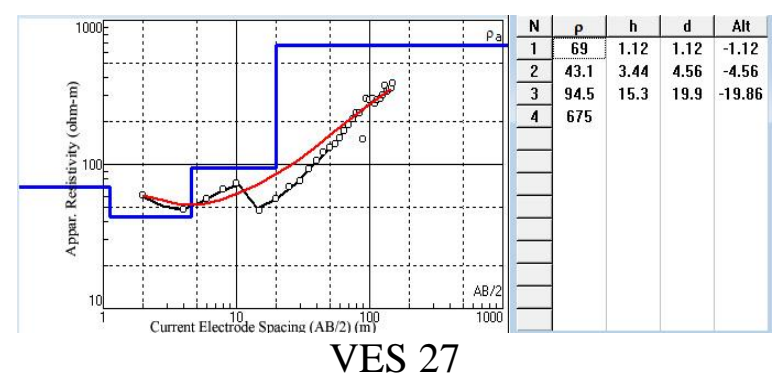

Figure 7. Interpretation of VES curves - HA-type

VES 22, 26 and 27 have the topsoil with resistivity values ranging from $17.9 \mathrm{ohm}-\mathrm{m}$ to $69 \mathrm{ohm}-\mathrm{m}$, showing the signs of fine particles along with clay content. The minimum 
and maximum thickness of the topsoil layer vary from $1.05 \mathrm{~m}$ to $1.70 \mathrm{~m}$. The VES curves of HA type indicate a massive rock formation with highly contrasting resistivity values ranging from $675 \mathrm{ohm}-\mathrm{m}$ to $11836 \mathrm{ohm}-\mathrm{m}$. As these HA curves show the second layer with resistivity ranges lesser than the topsoil layer and there is an increase in the resistivity of the successive layer, it is obvious that the second layer is highly weathered and cannot be expected as the groundwater potential.

\section{QH type curve}

The morphology of this type of curve is defined by the resistivity sequence of $\rho_{1}<\rho_{2}<\rho_{3}>\rho_{4}$. The VES 6 consists of a QH type curve, where the resistivity of first, the second and the third layers are defined by relatively high resistivity ranges from $50.2 \mathrm{ohm}-\mathrm{m}, 88.3 \mathrm{ohm}-\mathrm{m}$, and $869 \mathrm{ohm}-\mathrm{m}$ respectively. The fourth layer shows relatively fewer resistivity values $214 \mathrm{ohm}-\mathrm{m}$, indicating highly weathered zones in association with fracture zones. In general a QH type curve indicates good groundwater potential zones. Figure 8 shows the interpretation of VES curves - QH-Type.

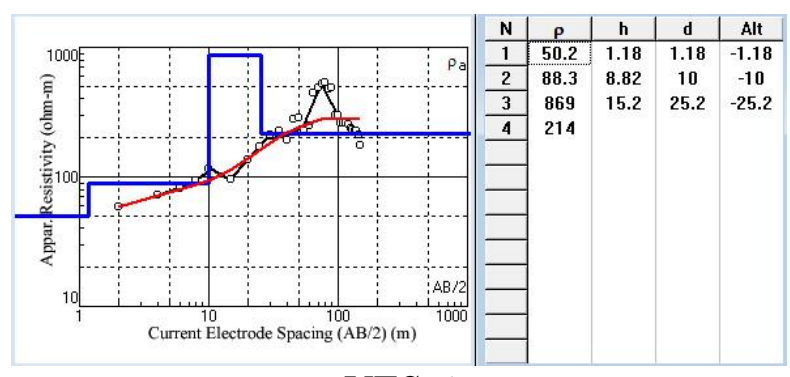

VES 6

Figure 8. Interpretation of VES curves - QH-type

\section{Conclusion}

The Vertical Electrical Sounding (VES) of Schlumberger configuration survey was performed in 27 locations within the study area to find out the groundwater potential zones in Nandi river basin. From the VES survey data, the four layered KH, AA, HK, $\mathrm{HA}$, and QH type curves, accounting for $59.26 \%, 22.22 \%, 3.70 \%, 11.11 \%$, and $3.70 \%$, respectively, were generated. Based on the VES survey investigation, VES of 3, 7, 10, $11,13,14,17,19,20$ and 21 belonging to $\mathrm{KH}$ type curve show good groundwater potential under the depths ranging from 3.69 to $32.5 \mathrm{~m}$. The VES 4, 5, 8, 15,18 and 24 display the origin of the third layers at relatively shallow depth, implying the presence of clay formation or the temporary groundwater yield. The AA type curve of VES 25 reveals the high probability of groundwater at a depth of $10 \mathrm{~m}$ and the occurrence of groundwater is the most doubtful in case of VES 12. In addition, VES of 1, 2, 9 and 23 of AA type unveil the absence of any fractured rock layers up to the depth of maximum investigation, leading to poor groundwater potential. The HK type curve of the VES 16 indicates moderate groundwater potential below depths of $18.6 \mathrm{~m}$. With the VES 22, 26 and 27 of HA type; poor groundwater potential can be expected. The VES 6 defined by QH type infers good groundwater potential zones below the depths of $25.2 \mathrm{~m}$. Hence, from the geoelectrical resistivity survey investigation, the location of groundwater potential zones were identified. Also the groundwater recharge potential zones are fully depend on the environmental factors like rainfall and climatic conditions. 
Acknowledgements. The authors would like to thank SRM Institute of Science and Technology and GRT Institute of Engineering \& Technology for providing all necessary facilities and constant encouragements for doing this research work.

\section{REFERENCES}

[1] Ahamed, A. J. Loganathan, K. Ananthakrishnan, S. Ahmed, J. K. C. Ashraf, M. A. (2016): Evaluation of Graphical and multivariate statistical methods for classification and evaluation of Groundwater in Alathur block, Perambalur District, India. - Applied Ecology and Environmental Research 15(3): 105-116.

[2] Amidu, S. A., Olayinka, A. I. (2006): Environmental assessment of sewage disposal systems using 2D electrical resistivity imaging and geochemical analysis: A case study from Ibadan, Southwestern Nigeria. - Environmental Engineering, Geosciences 7(3): 261-272.

[3] Barseem, M. S., El Lateef, T. A. A., El Deen, H. M. E., Abdel Rahman, A. A. A. A. (2015): Geoelectrical exploration in South Qantara Shark Area for supplementary irrigation purpose-Sinai-Egypt. - Hydrology Current Research 6: 207. DOI: 10.4172/2157-7587.1000207.

[4] Huang, B. B., Niu, J. T., Gui, F. L., Zhang, X. H. (2017): Water resources deployment model for Pingshui river basin. - Applied Ecology and Environmental Research 15(3): 985-998.

[5] Krishnamurthy, N. S. Chandra, S., Kumar, D. (2008): Geophysical Characterization of Hard Rock Aquifers. - In: Ahmed, S., Jayakumar, R., Salih, A. (eds.) Groundwater Dynamics in Hard Rock Aquifers. Springer, Dordrecht.

[6] Mahmoud, S. H. (2014): Delineation of potential sites for groundwater recharge using a GIS-based decision support system. - Environ Earth Sci 72: 3429-3442. DOI: $10.1007 / \mathrm{s} 12665-014-3249-\mathrm{y}$.

[7] Musy, A., Higy, C. (2011): Hydrology - A Science of Nature. -Taylor and Francis Group, LLC, New York.

[8] NRSA (2008): Groundwater Prospect Mapping Using Remote Sensing and GIS. Rajiv Gandhi National Drinking Water Mission Project Manual. - National Remote Sensing Agency, Hyderabad.

[9] Ramanuja Chary, K. R. (2012): Geophysical techniques for groundwater exploration. Professional Books Publisher, Hyderabad. ISBN: 978-81-909728-2-6.

[10] Reynolds, J. M. (2011): An Introduction to Applied and Environmental Geophysics, 2nd ed. - Wiley-Blackwell, Chichester.

[11] Salas, J. D., Govindaraju, R. S., Anderson, M., Arabi, M., Frances, F., Suarez, W., Lavado-Casimiro, W. S., Green, T. R. (2014): Modern Water Resources Engineering Introduction to Hydrology. Handbook of Environmental Engineering, Vol. 15. Springer, New York. DOI: 10.1007/978-1-62703-595-8.

[12] Shakib, H. S., Shojarastegari, H. (2017): Climate change impacts and water resources management. - Applied Ecology and Environmental Research 15(4): 741-754.

[13] Singhal, B. B. S. (2008): Nature of Hard Rock Aquifers: Hydrogeological Uncertainties and Ambiguities. - In: Ahmed, S., Jayakumar, R., Salih, A. (eds.) Groundwater Dynamics in Hard Rock Aquifers. Springer, Dordrecht.

[14] Venkateswaran, S., Ayyandurai, R. (2015): Groundwater potential zoning in upper Gadilam river basin Tamil Nadu. - Aquatic Procedia 4: 1275-1282.

[15] Venkateswaran, S., Vijay Prabhu, M., Karuppannan, S. (2014): Delineation of groundwater potential zones using geophysical and GIS techniques in the Sarabanga sub basin, Cauvery River, Tamil Nadu, India. - International Journal of Current Research 2(1): 58-75. 